\title{
Numerical Analysis of Dynamic Characteristics of Thermowell Based on Two-Way Thermo-Fluid-Solid Coupling
}

\author{
Yongchao Zhang $\mathbb{D}^{1}{ }^{1}$ Lilin Ding, ${ }^{1}$ Mei Qi, ${ }^{1}$ and Guangxia Bei $\mathbb{D}^{2}$ \\ ${ }^{1}$ College of Mechanical and Electronic Engineering, Shandong University of Science and Technology, Qingdao 266590, China \\ ${ }^{2}$ Engineering Training Center, Shandong University of Science and Technology, Qingdao 266590, China
}

Correspondence should be addressed to Yongchao Zhang; jdxzyc@sdust.edu.cn and Guangxia Bei; skd994475@sdust.edu.cn

Received 4 July 2021; Revised 10 November 2021; Accepted 16 November 2021; Published 3 December 2021

Academic Editor: Giuseppe Ruta

Copyright (c) 2021 Yongchao Zhang et al. This is an open access article distributed under the Creative Commons Attribution License, which permits unrestricted use, distribution, and reproduction in any medium, provided the original work is properly cited.

\begin{abstract}
Because thermowells are prone to fatigue damage in petroleum cracking gas pipelines, in this paper, the LES method is used to simulate the flow around thermowells through two-way thermal-fluid-solid coupling, the internal causes of thermowell damage are explored, and measures for improving the thermowell safety are proposed. According to this study, when high-speed, hightemperature gas passes the thermocouple bushing, the main factors affecting the structural safety of the thermocouple bushing are the alternating stress caused by the vortex falling off, the thermal stress cycle due to the temperature gradient, and the pressure gradient impacted by the gas. Furthermore, this paper proposes improving the thermowell safety by installing the interference devices and optimizing the installation angle. The improvement measures were studied by conducting a two-way thermal fluidstructure coupling simulation. The results of this study show that after installing the interference device and optimizing the installation angle the displacement deformation of the thermowell and the equivalent stress is reduced by $57.2 \%$ and $72.1 \%$, respectively, which indicates the safety improvement of the thermowell structure and the effectiveness of the method. The research contents of this paper can provide guidance for the installation and use of thermocouple bushing.
\end{abstract}

\section{Introduction}

In the petrochemical industry, the temperature of petroleum cracking, as an important monitoring and control parameter, is usually measured by a thermocouple. Because of the high air temperature and flow rate in the pipeline, the bushing must be used to protect the thermocouple. However, the fracture often occurs in the application, which seriously affects the continuity of oil cracking gas production.

According to the theory of vortex-induced vibration, in subsonic transverse flow, vortex shedding occurs when there is enough trailing edge at the tail of any nonstreamlined object [1]. With the cantilever thermowell in the pipeline, when the vortex falls off periodically on both sides of the thermowell, periodic lift and resistance are generated around the thermowell, thereby inducing thermowell vibration. When the vibration frequency is close to that of the thermowell, resonance occurs at the natural frequency of the pipe $[2,3]$, leading to the broken thermowell. When hightemperature gas is passing, the thermowell is thermally deformed due to the large temperature gradient in its height direction. The thermal stress changes repeatedly with the rapid and repeated temperature changes, resulting in fatigue damage to the material. The thermal stress cycle caused by the temperature gradient is a major cause of fatigue failure of the thermowell [4-6]. Mudhaffar et al. [7] researched the bending behavior of an advanced functionally graded ceramic-metal plate resting on a viscoelastic foundation and subjected to a hygro-thermo-mechanical load; both linear and nonlinear influences of temperature on the bending response were investigated. Merazka et al. [8] studied the hygro-thermo-mechanical bending responses of a simply supported FG-plate resting on a Winkler-Pasternak elastic foundation, the effects of the temperature, elastic foundation parameters, shear deformation, geometrical parameters, 
axial and transverse shear stresses of the FG-plate, and power-law-index on the dimensionless deflections which were discussed. Therefore, to simulate the real operating conditions and explore the internal mechanism of thermowell damage, two-way thermal-fluid-solid coupling calculations are required.

Two-way thermal-fluid-solid coupling has attracted more and more attention and has been used by researchers in solving practical engineering problems. Lu et al. [9] developed a modified multiextremum response (MRSM) to approximate the multifailure nonlinear dynamic responses of aeroengine components under high-temperature and rotating speed loads, concerning fluid-thermal-structure interaction. Keshtegar et al. [10] demonstrated the applicability of the proposed method (MKMEF) by considering the fluid-thermal-solid interaction and analyzing the probability of radial operation deformation of a certain aeroengine high-pressure turbine blisk. Zhou et al. [11] found that the heat transfer efficiency at the shell side can be improved by enhancing the heat transfer temperature difference and the convection due to the vortex generated by the shell side fluid. Gengwang et al. [12] used the LES method to conduct thermal-fluid-solid coupling numerical simulations of T-shaped pipelines in petroleum, chemical industries, nuclear power, and other pipeline systems and explored the causes of thermal fatigue of pipelines. Ding et al. [13] analyzed the vibration response of the structure and the variation law of the temperature field; they also studied the average Nusselt number and the position of the maximum local Nusselt number based on the dual-degreeof-freedom flow-induced vibration-heat transfer coupling characteristics of a single thermostatic tube. The aforementioned researches contribute to the development of the coupled calculations of thermal fluids and structures and also help the calculation in this paper.

According to literature review, current research on the causes of thermocouple thermowell damage is based mostly on semiempirical theoretical analysis and experiments. Unfortunately, the studies on the stress of the thermocouple thermowell by the CFD method are based mainly on simple stress analysis with the coupled pressure and temperature fields, and few have considered the impacts of gas temperature and compressibility on the thermocouple thermowell [14, 15]. The petroleum cracked gas pipeline transports high-temperature and high-speed gas, and gas temperature and compressibility affect the force and deformation of the thermocouple thermowell [16-20]; therefore, not considering their influence, the calculation results would be inconsistent with the reality $[21,22]$.

The lateral vibration caused by resistance and vortex shedding affects the thermowell safety. Many studies on reducing drag and damping vibration have been conducted by scholars. Rui and Sun [23] using the K- $\omega /$ SST turbulence model conducted a numerical simulation of $\mathrm{V}$-shaped grooves with different depths arranged on the cylindrical surface and found that $\mathrm{V}$-shaped grooves have drag reduction effects. Zhao et al. [24] using OpenFOAM performed numerical simulations on the flow around the cylinder under the attached prism, and their study indicated that the attached prism could effectively improve the pressure distribution on the cylinder surface, weaken the pressure differential resistance, and reduce the lift force received by the cylinder. Islam et al. [25], based on a single-time lattice Boltzmann method (SRTLBM), adding a splitter on the upstream of Square column, analyzed the influence of the splitter-side column winding and the swirls of the vortex. Grioni [26] studied the $\mathrm{RE}=2 \times 10^{5}$ string double-cylinder bypass using a scale adaptive simulation (SAS) turbulence model. It was found that the disturbance between the two-column winding reduces the rear column resistance and the front post has a certain effect on the devote law of the rear column vortex.

Therefore, based on previous studies, this paper takes thermowell as the research object and conducts numerical simulations on it. First, the flow around a single thermowell was analyzed. From the aspects of temperature field, pressure field, and gas compressibility, the surface stress and wake field changes of the thermowell were studied, and the causes of the thermowell breakage at the welding point were explored. Then, because the thermowell is prone to breakage in practice, the corresponding structure was improved, and the improved structure model was numerically simulated to analyze its influence on the thermowell. The research results are of great significance to the safe applications of thermowells in industrial fields.

\section{Theoretical Basis of Thermal-Fluid- Solid Coupling}

2.1. Fluid Control Equations. The fluid flow follows basic physical conservation laws: conservation of mass, conservation of momentum, and conservation of energy. For general compressible Newtonian fluids, the law of conservation can be described by the following governing equations.

Mass conservation equation:

$$
\frac{\partial \rho}{\partial t}+\frac{\partial\left(\rho u_{x}\right)}{\partial x}+\frac{\partial\left(\rho u_{y}\right)}{\partial y}+\frac{\partial\left(\rho u_{z}\right)}{\partial z}=0,
$$

where $u_{x} u_{y}$, and $u_{z}$ are the velocity components in $x, y$, and $z$ directions, $\mathrm{m} / \mathrm{s}$; $t$ is time, $s ; \rho$ is density, $\mathrm{kg} / \mathrm{m}^{3}$.

Momentum conservation equation:

$$
\frac{\partial \rho_{v}}{\partial t}+\nabla\left(\rho_{f} v v-\tau_{f}\right)=f_{f},
$$

where $t$ is the time; $f_{f}$ is the volume force vector; $\rho_{f}$ is the fluid density; $v$ is the fluid velocity vector; $\tau_{f}$ is the shear force tensor; $\nabla$ is the Hamiltonian differential operator.

$$
\nabla=i \frac{\partial}{\partial x}+j \frac{\partial}{\partial y}+k \frac{\partial}{\partial z}
$$

The shear force tensor equation can be expressed as follows:

$$
\tau_{f}=(-p+\mu \nabla v) I+2 \mu e .
$$


In the formula, $p$ is fluid pressure; $\mu$ is dynamic viscosity; $e$ is velocity stress tensor; $e=1 / 2\left(\nabla v+\nabla v^{T}\right)$.

Energy conservation equation:

$$
\frac{\partial(\rho E)}{\partial t}+\nabla[u(\rho E+p)]=\nabla\left[K_{e f f} \nabla T-\sum_{j} h_{j} J_{j}+\left(\tau_{e f f} u\right)\right]+S_{h},
$$

where $E$ is the total energy of fluid micelles, J/kg, including internal energy, kinetic energy, and potential energy; $E=h-p / \rho+u^{2} / 2 ; h$ is enthalpy, J/kg; $h_{j}$ is the $j$ component of enthalpy, J/kg; $K_{\text {eff }}$ is effective thermal conductivity, W/ $(\mathrm{m} \cdot \mathrm{K}) ; K_{\text {eff }}=k+K_{t} ; K_{t}$ is turbulent thermal conductivity determined by the turbulence model; $J_{j}$ is the $j$ component of diffusion flux; $S_{h}$ includes chemical reaction heat and other user-defined volumetric heat source items.

2.2. Solid Governing Equation. The governing equation of fluid-induced solid vibration and displacement [16] is

$$
M_{s} \frac{\partial^{2} r}{\partial t^{2}}+C_{s} \frac{\partial r}{\partial t}+K_{s} r+\tau_{s}=0,
$$

where $M_{s}$ is mass matrix; $C_{s}$ is damping matrix; $K_{s}$ is stiffness matrix; $r$ is solid displacement; $\tau_{s}$ is solid stress.

2.3. Coupling Equations. The fluid-solid interface should be equal to the displacement, heat flow, temperature, and stress, etc. of the fluid and the solid [17]:

$$
\begin{gathered}
n \tau_{f}=n \tau_{s} r_{f}=r_{s}, \\
q_{f}=q_{s} T_{f}=T_{s},
\end{gathered}
$$

where $q$ is heat flux; $T$ is temperature; the subscript $f$ indicates fluid; the subscript $s$ denotes solid.

2.4. Elastomer Equilibrium Differential Equation. The stress, deformation, and displacement of the object are obtained after solving the equilibrium differential equation of the spatial elastic body problem. The balanced differential equation of the spatial elastic body problem is

$$
\left\{\begin{array}{l}
\frac{\partial \sigma_{x}}{\partial x}+\frac{\partial \tau_{y x}}{\partial y}+\frac{\partial \tau_{z x}}{\partial z}+f_{x}=0 \\
\frac{\partial \sigma_{y}}{\partial y}+\frac{\partial \tau_{z y}}{\partial z}+\frac{\partial \tau_{x y}}{\partial x}+f_{y}=0 \\
\frac{\partial \sigma_{z}}{\partial z}+\frac{\partial \tau_{x z}}{\partial x}+\frac{\partial \tau_{y x}}{\partial y}+f_{x}=0
\end{array}\right.
$$

\section{Physical Model and Boundary Conditions}

3.1. Geometric Model. According to the process size provided by an enterprise, the geometric model of the thermowell was established, as shown in Figure 1. Detailed dimensions are presented in Table 1. To improve the calculation efficiency, the physical model was simplified, only the area below the installation position of the thermowell device is taken as the flow channel calculation domain, and $260 \mathrm{~mm}$ is taken before and after the pipe.

3.2. Boundary Conditions. For the fluid field, the inlet is the velocity inlet, and the outlet is the pressure outlet. Except for the casing wall, all other surfaces are set as the no-slip wall condition. The specific parameters are shown in Table 2. The boundary conditions for the solid domain were set in the Transient Structural module. Remote Displacement fixed constraints were added to the top of the casing to limit the translational and rotational motion of the casing in $X, Y$, and $Z$ directions.

The thermowell wall is set as the coupling surface, connecting the fluid domain to the solid domain to transfer data. The fluid domain transfers pressure and temperature loads to the solid domain, and the solid domain transfers deformation to the fluid domain to realize the bidirectional transfer of heat flow and solid multiphysical field data.

3.3. Grid Division and Independence Verification. In this paper, the hybrid grid method is used to divide the overall computational domain model, in which the tetrahedral unstructured grid is used in the pipeline part and the hexahedral structured grid is used in the thermocouple casing part. In addition, ten layers of the boundary layer are set on the casing wall and $y^{+} \approx 1$ is set, and the casing wake area is also encrypted. The meshing is shown in Figure 2.

The numerical simulation in this paper involves massive multifield coupling calculation, so the grid-independent verification of the entire calculation domain was performed. As shown in Table 3, when the number of grids exceeds 1.32 million, the output flow of the computing domain tends to be stable without remarkable fluctuation; thus, this paper takes the magnitude of 1.32 million grids in the numerical simulation.

\section{Numerical Analysis Results}

In this paper, the fluid calculation software CFX and Transient Structural were employed to conduct the bidirectional heat fluid-structure coupling. In the subcritical region, the large eddy simulation (LES) method has a better simulation effect on turbulence, so the LES turbulence model was selected in this paper, and the numerical simulation was conducted according to the flow chart in Figure 3.

\subsection{Flow Field Analysis}

4.1.1. Speed Analysis. The cross section of the velocity distribution contour by numerical simulation is plotted in Figure 4. As shown in the figure, when $T=3$ ( $T$ is the number of cycles), a high-speed area is generated on the backflow surface of the thermowell while a high-speed recirculation area is formed on the facing surface. With the further impact of the high-speed gas, at $T=7$, the gas turbulence destroys 


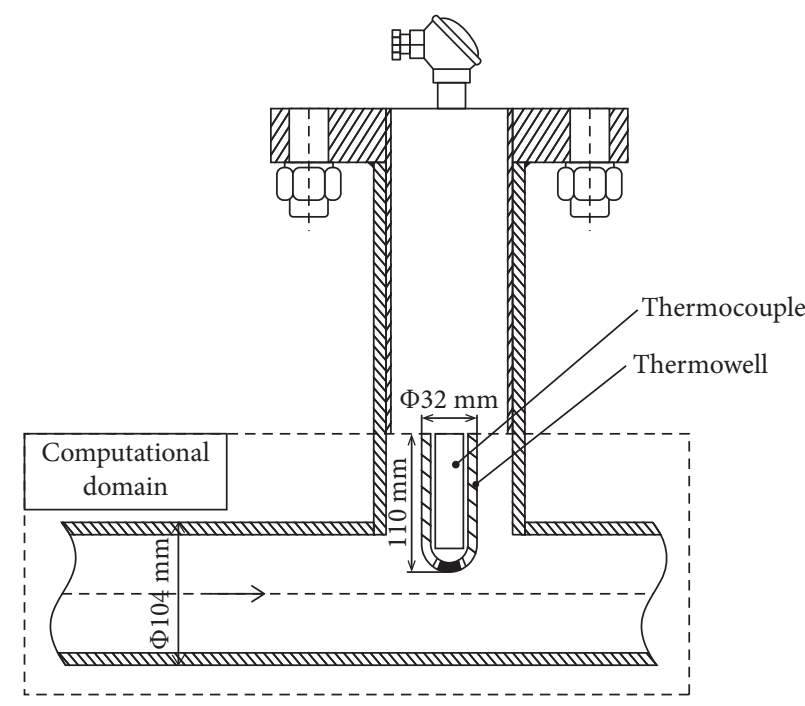

(a)

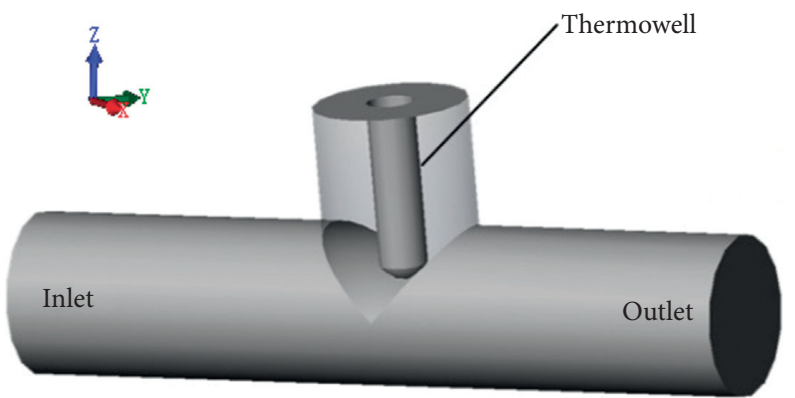

(b)

Figure 1: Geometric parameters. (a) Geometric section view. (b) Computational domain.

TABLE 1: Geometric dimensions of thermowell.

\begin{tabular}{lccc}
\hline Name & Inner diameter & Outside diameter & Height \\
\hline Size $(\mathrm{mm})$ & 28 & 32 & 110 \\
\hline
\end{tabular}

TABLE 2: Boundary conditions.

\begin{tabular}{lcccc}
\hline Pipeline medium state & Temperature $\left({ }^{\circ} \mathrm{C}\right)$ & Density $\left(\mathrm{Kg} / \mathrm{m}^{3}\right)$ & Inlet velocity $(\mathrm{m} / \mathrm{s})$ & Outlet pressure $(\mathrm{MPa})$ \\
\hline Gaseous & 849 & 0.45 & 170 & 0.96 \\
\hline
\end{tabular}

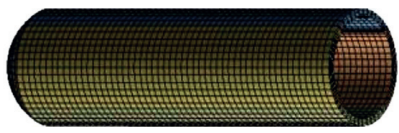

(a)

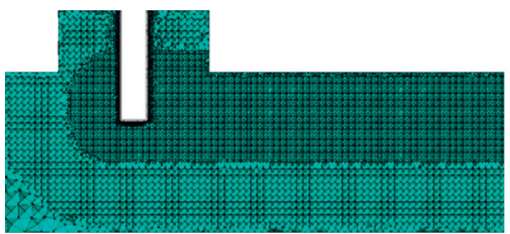

(b)

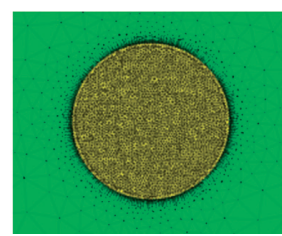

Figure 2: Meshing. (a) Solid domain meshing. (b) Fluid domain meshing.

TABLE 3: Grid independence verification.

\begin{tabular}{lcccccc}
\hline $\begin{array}{l}\text { The number of meshes/ten } \\
\text { thousand }\end{array}$ & 63 & 97 & 132 & 209 & 311 \\
\hline Outlet flow/kg/s & 0.614 & 0.629 & 0.651 & 0.650 & 0.649 \\
\hline
\end{tabular}

the recirculation areas on both sides of the upper surface of the fluid, with vortex rings appearing on both sides of the pipeline and an irregular initial vortex shedding. At $T=10$ and $T=12$, the gas gradually stabilizes in the pipeline with a regular vortex shedding and stable vortex rings on both sides of the thermowell.
4.1.2. Pressure Analysis. Figure 5 demonstrates the longitudinal section of the pressure distribution contour by numerical simulation. In the figure, at $T=3$, a local highpressure area forms on the upstream side of the thermowell due to the gas impact while localized low-pressure areas appear in the "dead water area" on the backflow surface and around the sides of the thermowell. When $T=10$ and $T=12$, the fully developed turbulent flow destroys the stability of the recirculation zone; hence, the pressure distribution in the pipeline gradually stabilizes. The flow around the sides and the bottom of the thermowell forms a local low-pressure 


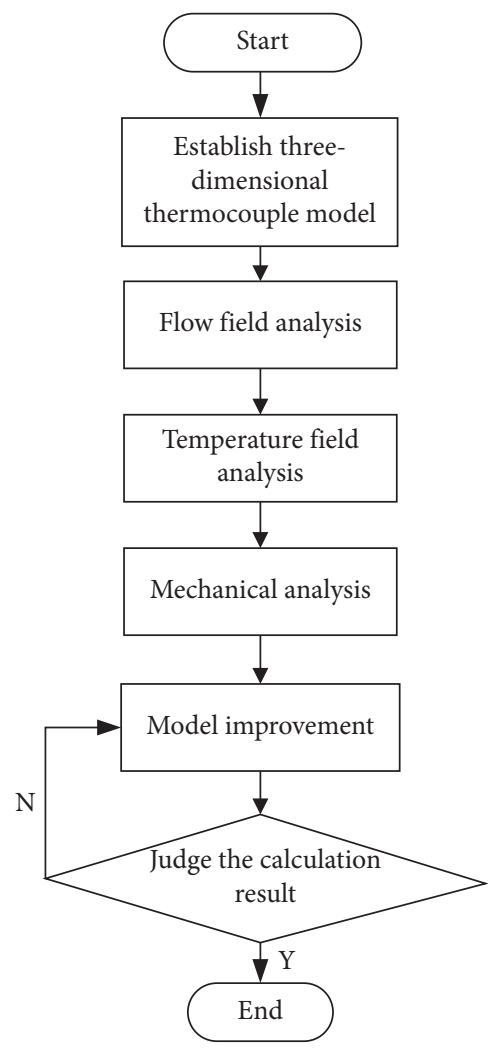

Figure 3: Calculation flow chart.

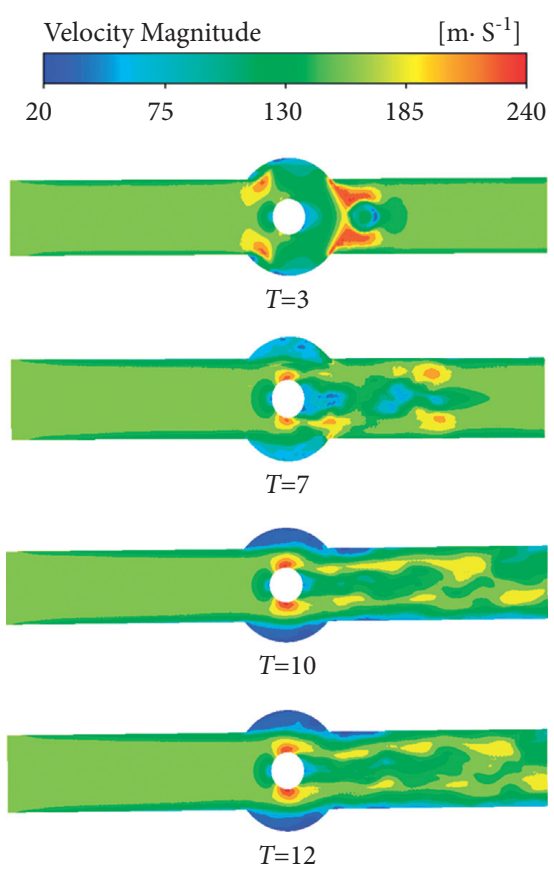

Figure 4: Velocity contours.

area, generating a large pressure gradient and forming a lowpressure area on the rear side of the thermowell with the vortex shedding. However, because of the high-speed gas

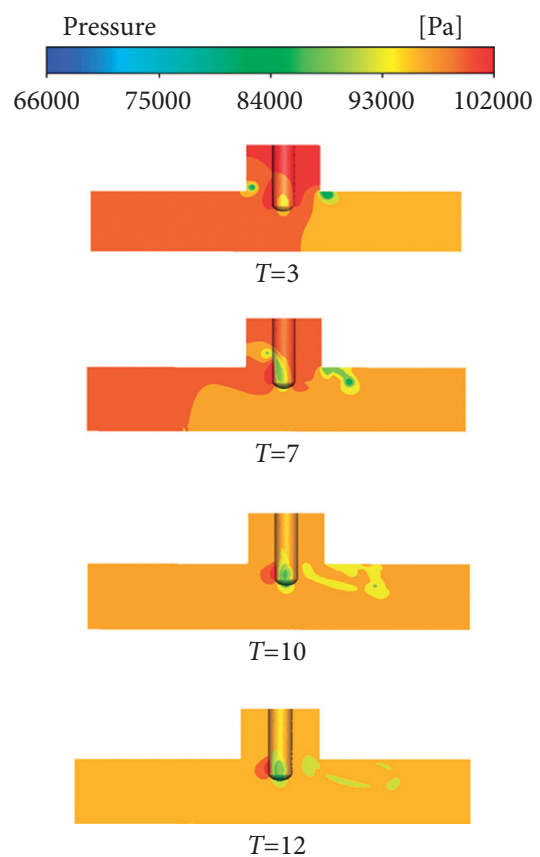

Figure 5: Pressure contours.

impact, the upstream side of the thermowell is within a local high-pressure region so that the thermowell is subjected to strong impact forces.

4.2. Influence of Gas Compressibility on Thermowell Deformation. The gas density changes along the height of the thermowell, as shown in Figure 6. When high-speed fluid impacts the thermowell, the gas compressibility is significant, having a nonnegligible effect on the alternating stress on the thermowell. Figure 7 depicts the profiles of casing deformation with time. It can be seen from the figure that, under the conditions of compressibility and incompressibility, the variation trends of casing deformation with time are similar, which increase gradually with time and finally reach stable states. However, the deformation is greater under the compressible condition, and it takes longer to reach the stable state. Under the compressible condition, due to the gas compressibility, the three-dimensional fluidity in the flow field is more intense, and the influence on the casing is greater.

To explore the variation law of casing deformation with time, the displacement in the $X$-axis direction within 5 seconds was monitored after casing deformation was stable. Figure 8 shows the displacement curve of the casing top section along the $X$-axis after deformation and stability. The figure demonstrates that the deformation curve periodically fluctuates around $0.96 \mathrm{~mm}$, indicating that the deformation of the casing is swinging. First, such deformation occurs because the surface pressure drag of the casing impacted by gas is very large; secondly, periodic shedding of vortices on both sides of the casing leads to periodic changes of lift and drag on the casing surface, resulting in vortex-induced vibration and swing deformation. When the thermowell material is close to its fatigue limit, it is prone to breakage. Figure 9 illustrates the breakage of the thermocouple thermowell. 


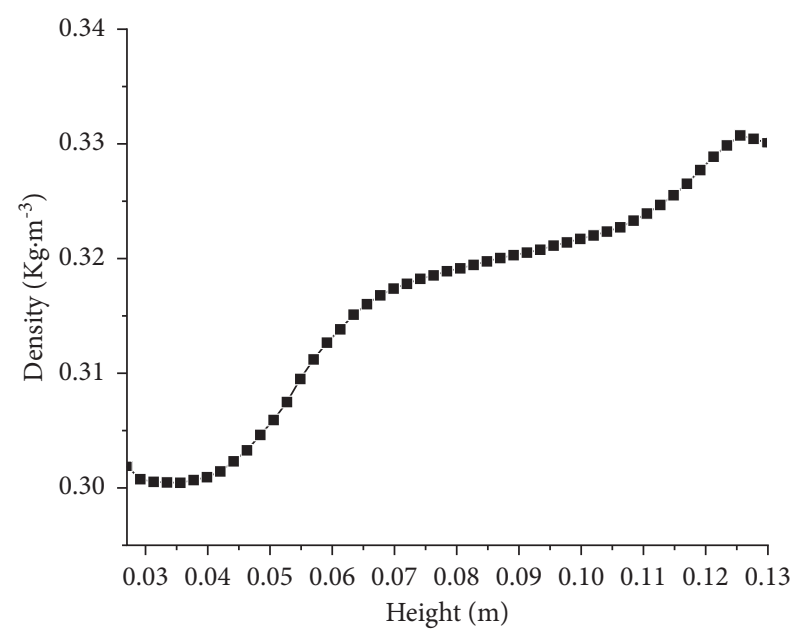

FIGURE 6: Variation of gas density along the height of thermowell.

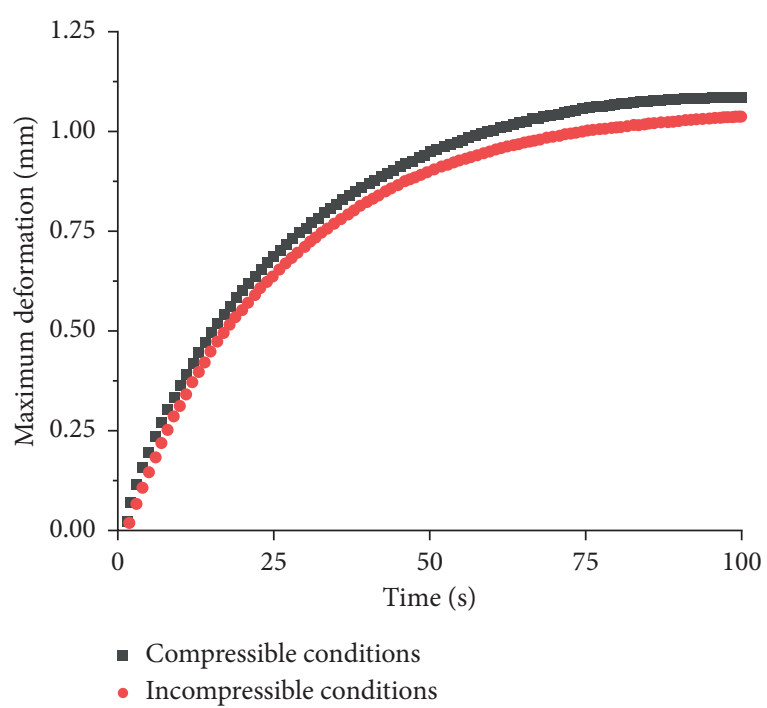

FIGURE 7: Effect of gas density on deformation of thermowell with time.

\subsection{Effects of Different Loads on Thermowell Deformation.} The contours of the deformation caused by three loads on the thermowell are shown in Figure 10. Figure 10(a) depicts the contour under the temperature load. In this figure, the deformation shows a regular gradient distribution, becoming smaller and smaller from the bottom to the top and presenting an expansion deformation compared with the pressure load. The bottom of the thermowell is deformed the most. Figure 10(b) shows the deformation contour of the thermowell under the pressure load. As shown in the figure, the bottom of the thermowell bends due to the fluid impact. The most serious deformation occurs at the bottom of the thermowell while the smallest deformation happens at the root of the thermowell; the maximum deformation is $0.986 \mathrm{~mm}$. The deformation contour of the thermowell under the combined pressure and temperature load is shown in Figure 10(c). The figure indicates that the two-way thermal-fluid-solid coupling simultaneously combines the influence of both flow field and temperature field on the

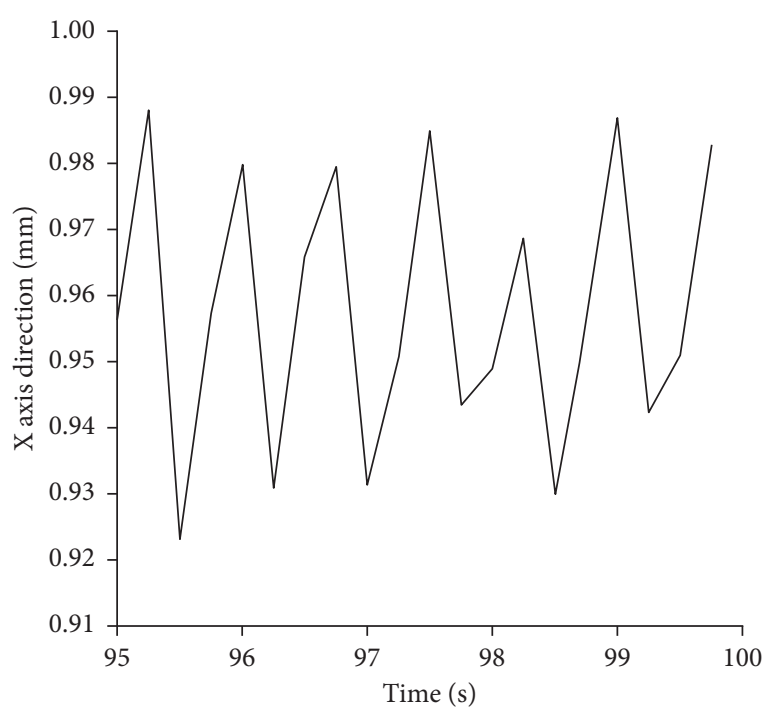

Figure 8: The displacement of the thermowell vertex in $\mathrm{X}$-axis under stable state.

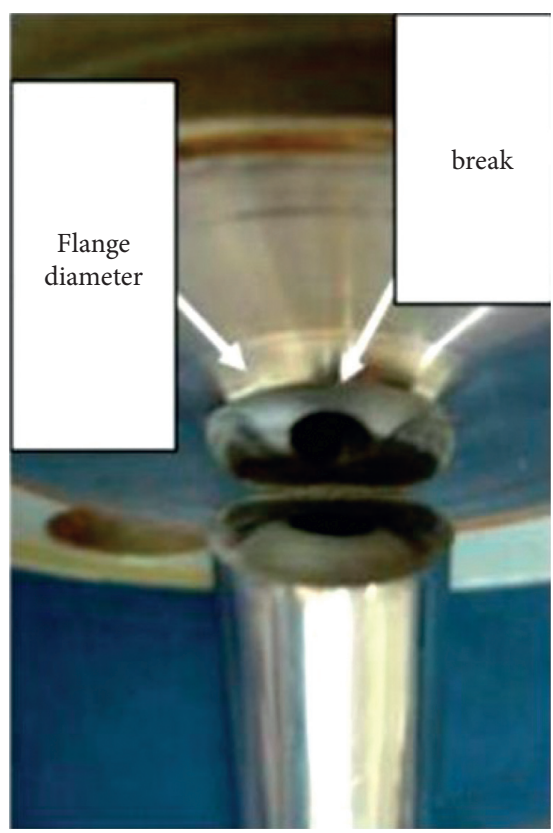

Figure 9: Fracture modes of thermowell.

thermowell. The thermowell tends to be not only bent by the fluid impact but also expanded due to the influence of temperature, so the maximum deformation of $1.12 \mathrm{~mm}$ obtained in the two-way thermal-fluid-solid coupling is slightly larger than the deformation due only to the pressure load. Different results under different load conditions prove indirectly that the results from the two-way thermal fluidstructure coupling are more suitable for the real stress environment of the thermowell.

4.4. Stress Distribution Cloud of Thermowell. The distribution contours of the equivalent stress of the thermowell at the equilibrium state are shown in Figure 11. From the stress 


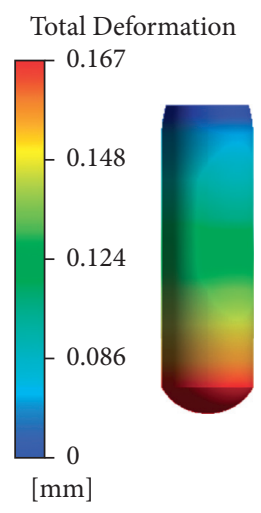

(a)

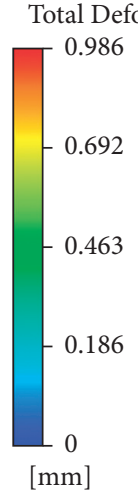

(b)

Figure 10: Contours of thermowell deformation. (a) Temperature load. (b) Pressure load. (c) Temperature + pressure load.

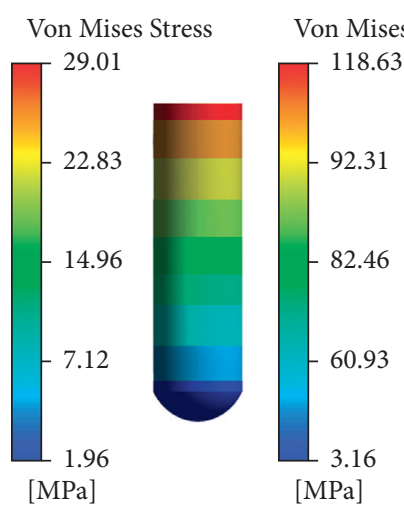

(a)

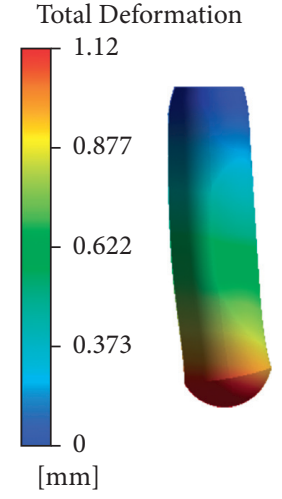

(c)

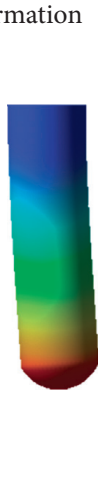

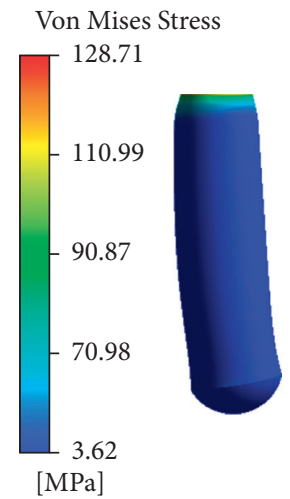

(c)

Figure 11: Contours of equivalent stress distribution of thermowell in equilibrium state. (a) Temperature load. (b) Pressure load. (c) Temperature + pressure load.

distribution contours, it can be found that the stress along the height direction changes remarkably, so this study focuses on the analysis of the stress distribution along the height direction. When the expansion or contraction due to the uneven temperature distribution is restricted during the heat exchange with the fluid, the thermowell generates a force that resists expansion or contraction, that is, thermal stress. Thermal stress is an addition to mechanical stress, which causes crack growth and fracture of the bowel [27]. Figure 11(a) shows the thermal stress changes along the height. The thermal stress has a gradient distribution, and the heat transfer is most uniform at the bottom of the thermowell, where the temperature difference and the thermal stress are the smallest. It was found that the surface temperature increases with Reynolds numbers due to the free convection dominant in the combined heat transfer process [28]. The mechanical stress and total stress change roughly along the height direction, as shown in Figure 12. The stress in the thermowell from 0.027 to $1.2 \mathrm{~m}$ is kept at 28.84 MPa, and it changes drastically above $1.2 \mathrm{~m}$. Because the total stress comes from the coeffect of pressure load and temperature load, its peak value is slightly greater than the mechanical stress. Although the total stress is the coeffect of the loads, it is not simply equal to the summation of thermal stress and mechanical stress because stress is a vector.

Based on the two-way thermo-fluid-solid coupling analysis, the gas compressibility and temperature load have an important effect on the deformation and stress distributions of the thermowell. When high-speed and hightemperature gas flows around the thermocouple thermowell, the alternating stress by the vortex shedding, the thermal stress cycle by the temperature gradient, and the pressure gradient by the gas impact are the main factors affecting the structural safety of the thermocouple thermowell.

\subsection{Influence of Thermowell Installation Angle on Flow Field.} To study the impact of thermowell installation angle on structural safety, numerical simulations were conducted on the thermowell with installation angles at $90^{\circ}, 60^{\circ}$, and $45^{\circ}$, respectively, bringing velocity distribution contours of the flow field. As shown in Figure 13, at different installation angles, the velocity clouds are noticeably different. At $45^{\circ}$ and $60^{\circ}$, the structural cross section changes remarkably with the installation angle, avoiding the vortex falling off due to the gas flow around the thermowell to a certain extent, and 


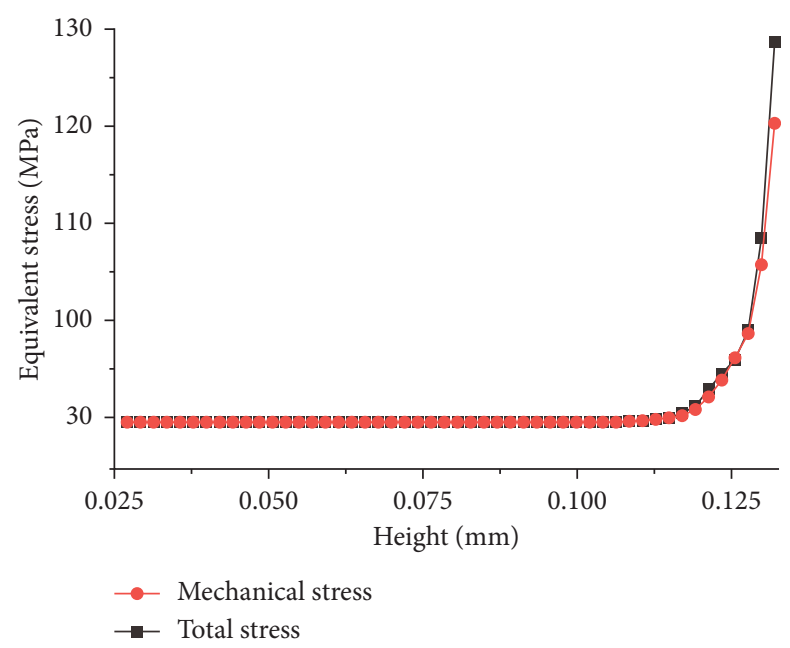

Figure 12: Equivalent stress distribution of the thermowell along the height direction under different loads in equilibrium state.

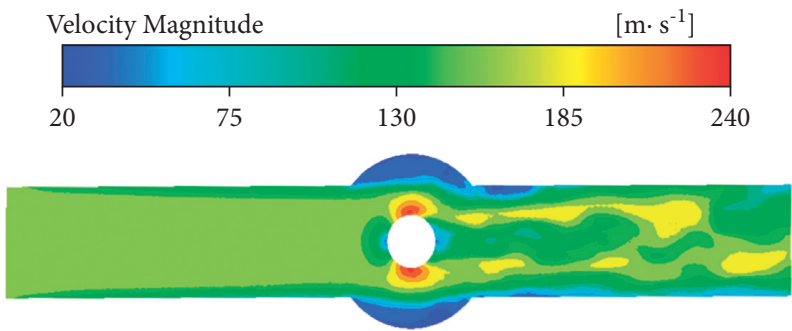

(a)

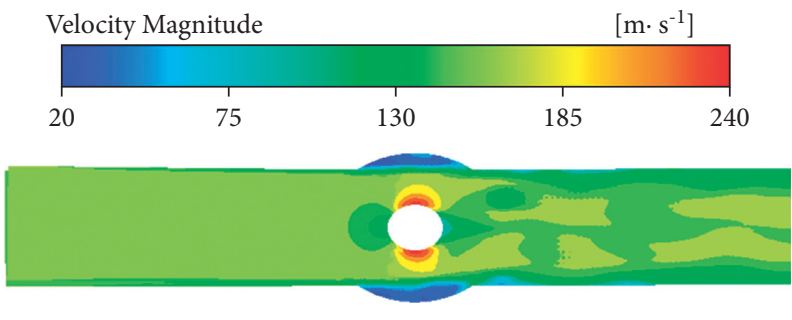

(b)

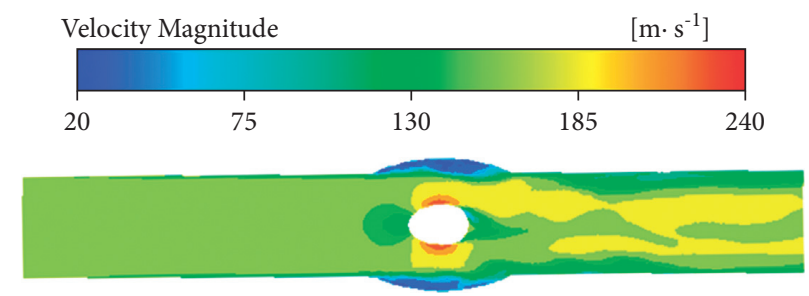

(c)

FIGURE 13: Velocity contours. (a) $90^{\circ}$ installation angular velocity cloud chart. (b) $60^{\circ}$ installation angular velocity cloud chart. (c) $45^{\circ}$ installation angular velocity cloud chart.

vortices by the wake of the thermowell are less than those at the $90^{\circ}$ angle.

It can be seen from Figure 14 that the Strouhal numbers at the installation angles of $60^{\circ}$ and $45^{\circ}$, respectively, are reduced by $14 \sim 28 \%$ compared to those at $90^{\circ}$. The reduction of the Strouhal number can effectively avoid the resonance of the thermowell structure and improve the safety of the thermowell structure.

The respective pressure distribution contours of the flow field at the installation angles of $45^{\circ}, 60^{\circ}$, and $90^{\circ}$ were obtained through numerical simulations and are presented in Figure 15. The figure indicates that, under the same insertion depth and working condition, the largest wall high-pressure distribution area is at $45^{\circ}$ and the smallest at $90^{\circ}$.

The above analysis demonstrates that optimizing the thermowell installation angle can reduce the number of vortices by the wake of the thermowell and thus avoid its resonance damage. However, if the thermowell installation angle changes, the area of the local high-pressure area will be increased, causing a more severe impact on the thermowell.

\section{Two-Way Thermo-Fluid-Solid Coupling Numerical Simulation of Thermocouple Thermowell Equipped with Interference Device}

To improve the safety of the thermowell structure and avoid the thermowell damage by long-term fluid impact and vortex-induced vibration, this paper proposes adding interference devices and optimizing the installation angle. Numerical simulation was conducted by the two-way thermal-fluid-solid coupling analysis technology to evaluate the proposed measures. 


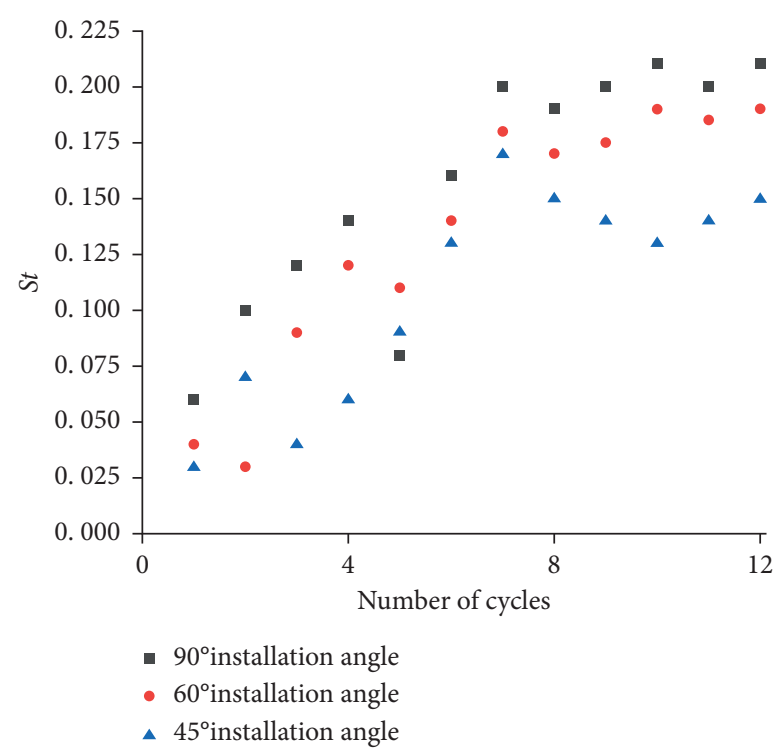

FIGURE 14: Variation of Strouhal number at thermowell different installation angles.

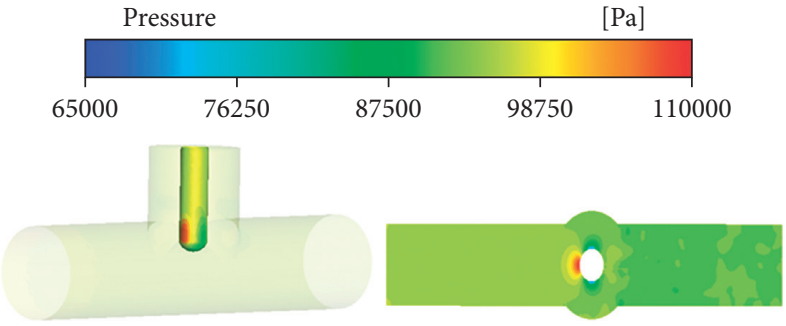

(a)
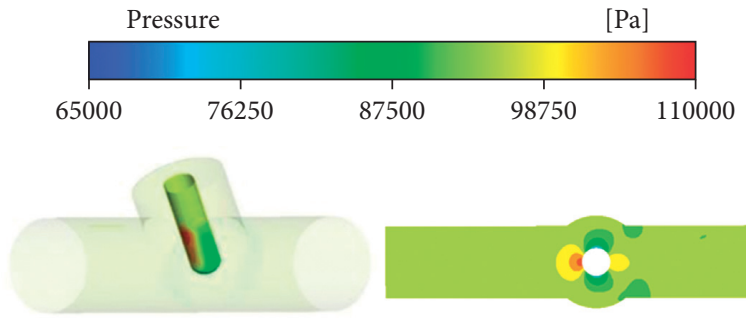

(b)

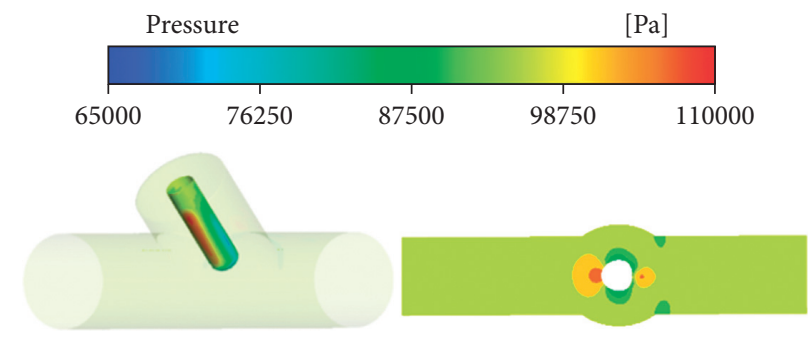

(c)

Figure 15: Pressure contours. (a) Pressure nephogram of $90^{\circ}$ installation angle. (b) Pressure nephogram of $60^{\circ}$ installation angle. (c) Pressure nephogram of $45^{\circ}$ installation angle.

\subsection{Physical Model and Boundary Conditions}

5.1.1. Geometric Model. The geometric model of the thermowell after adding the interference device and optimizing the installation angle is shown in Figure 16. In this paper, a thermowell with an installation angle of $60^{\circ}$ was selected for modeling, and the calculation domain is the same as the above setting.

5.1.2. Grid Partitioning and Grid Independence Verification. The structure of the jamming device is relatively complex. To improve the accuracy of the grid parameter selection, a more adaptable unstructured grid was adopted to partition the grid. To considerate the accuracy of numerical simulation and capture the flow phenomenon in the key parts of the flow field, the casing wall and wake area were properly encrypted. The meshing is shown in Figure 17.

Grid independence verification was performed on the overall computing domain, and the results are shown in Table 4. As can be seen from the table, when the number of grids exceeds 1.94 million, the outlet flow of the computing domain tends to be stable. Therefore, considering the existing computer hardware resources and computing efficiency, the scale of 1.94 million grids was used for numerical simulation.

5.1.3. Boundary Conditions. The boundary conditions of the fluid domain are set in Fluid Flow (CFX), whose specific parameters are shown in Table 1. The boundary conditions 


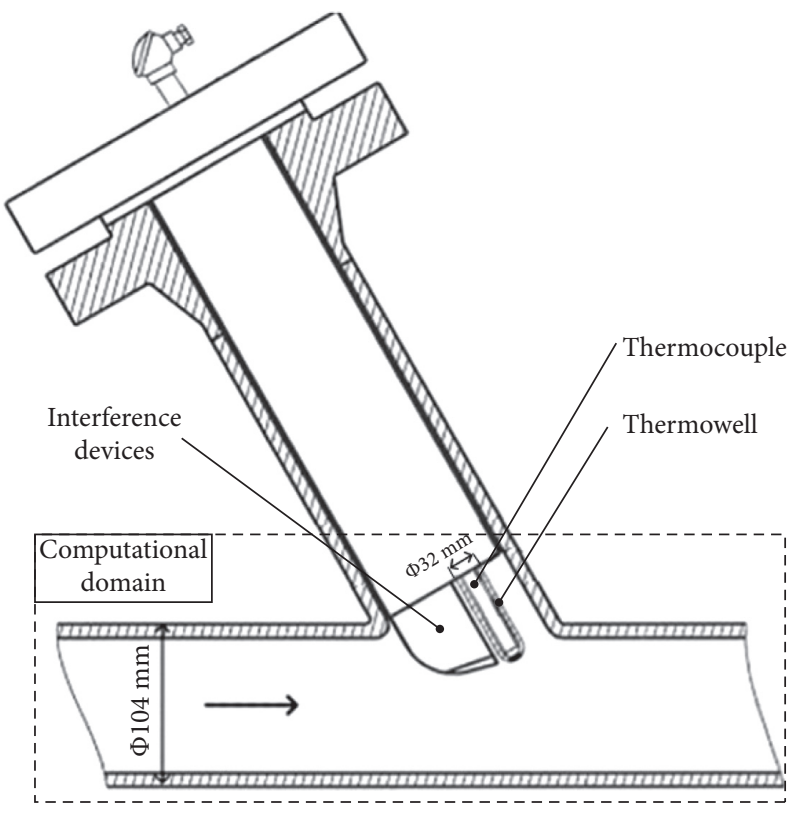

(a)

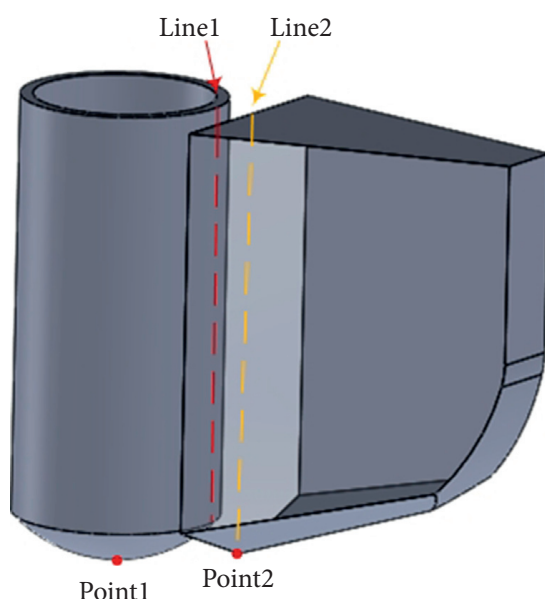

(b)

FIGURE 16: Geometric model.

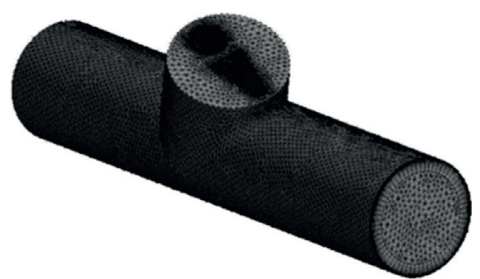

(a)

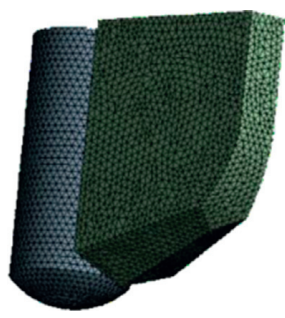

(b)

Figure 17: Meshing. (a) Fluid domain meshing. (b) Solid domain meshing.

TABLE 4: Grid independence verification.

\begin{tabular}{lccccc}
\hline $\begin{array}{l}\text { The number of meshes/ten } \\
\text { thousand }\end{array}$ & 86 & 129 & 194 & 292 & 438 \\
\hline Outlet flow/kg/s & 0.624 & 0.632 & 0.636 & 0.636 & 0.635 \\
\hline
\end{tabular}

of the solid domain are also set in the Transient Structural analysis module (Transient Structural). Since the thermowell and the interference device are both cantilevered and installed in the pipeline, the same fixed constraints are applied with Remote Displacement adopted in the thermowell and at the top of the interference device to limit the displacement and rotational movement in the $X, Y$, and $Z$ directions. Both thermowell and wall surface of the interference device are set as the coupling surfaces, serving as interfaces connecting the fluid domain and the solid domain to transfer data.

\subsection{Flow Field Analysis}

5.2.1. Velocity Analysis. The velocity contours of the cross section and the longitudinal section were obtained from numerical simulations, as shown in Figure 18. It can be seen from the figure that the gas flow is becoming stable after $T=7$. The inclined structures on both sides of the interference device, though conducive to the flow of gas in the pipeline, cannot eliminate the high-speed return area. Compared with Figure 4, the velocity cloud has been remarkably improved. With the interference device, the speed is "divided" into three parts in the lateral interface behind the thermowell, and there the high-speed flow area is formed due to structural interference at both sides and in the middle, eliminating the vortex shedding caused by trailing on both sides of the structure. The interference device changes the flow field and avoids vortex-induced vibration of the thermowell.

5.2.2. Pressure Analysis. The pressure distribution of the longitudinal section was obtained by the simulation. Figure 19 presents the results. As shown in the figure, the gas pressure distribution in the pipe tends to be stable after $T=7$; a local high-pressure area appears on the upstream side of the interference device, and two small local low-pressure areas appear on both sides of the structure, resulting in a 


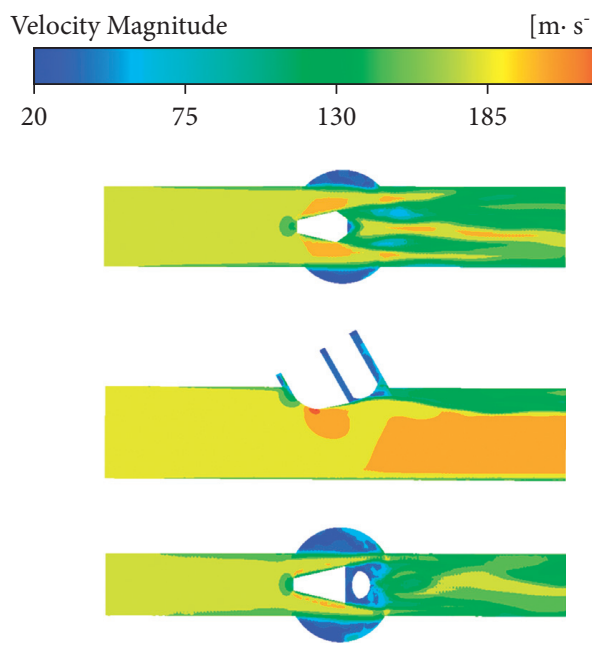

(a)
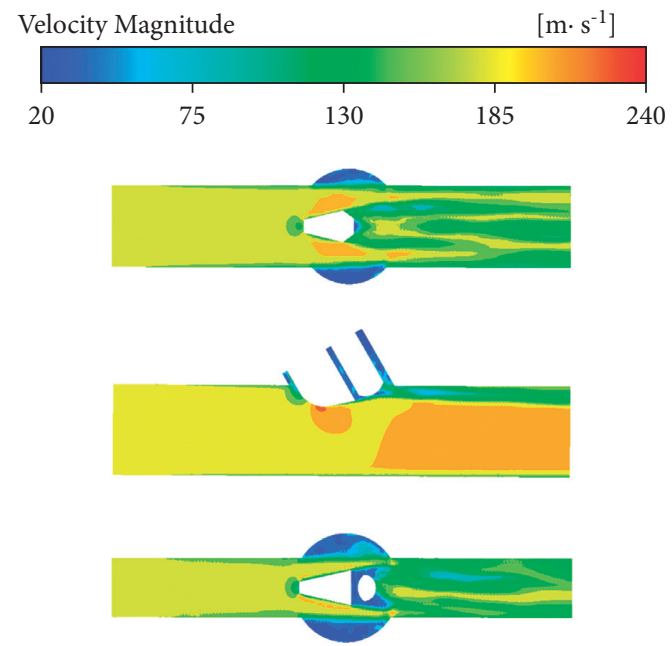

(b)
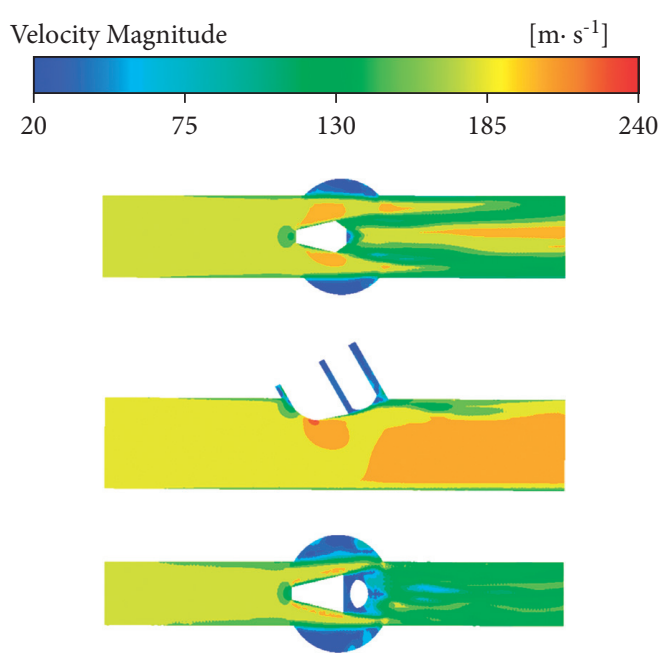

(c)

FIGURE 18: Velocity contour. (a) $T=7$. (b) $T=10$. (c) $T=12$.

small local pressure gradient with a limited impact on the interference device. With the full development of the flow, the local low-pressure areas on both sides gradually become smaller as the gas flows in the pipe; therefore, the pressure distribution on the rear side of the pipe also gradually stabilizes, and the area of the low-pressure area decreases gradually till it disappears. At $T=12$, the low-pressure areas on both sides of the thermowell disappear completely, so the fluid pressure is evenly distributed on the thermowell wall.

Based on the above analysis, with the interference device and the change of the flow law, the "Carmen vortex" shedding on both sides of the thermowell is eliminated, which avoids the resonance of the thermowell structure; the interference device can also prevent the thermowell from direct exposure to gas shock. At the same time, the top contact area of the interference device structure is large, which can ensure the safety of its own structure.

5.2.3. Vorticity Analysis. Figure 20 shows the vorticity contours of the wake region of a single thermowell and thermowell with an interference device. It can be seen from Figure 20(a) that after the boundary layer separation occurs on the casing surface, due to the occasional viscosity of the fluid, the vortex that falls off periodically appears downstream of the casing, which is " $2 S$ " shaped and has a long 


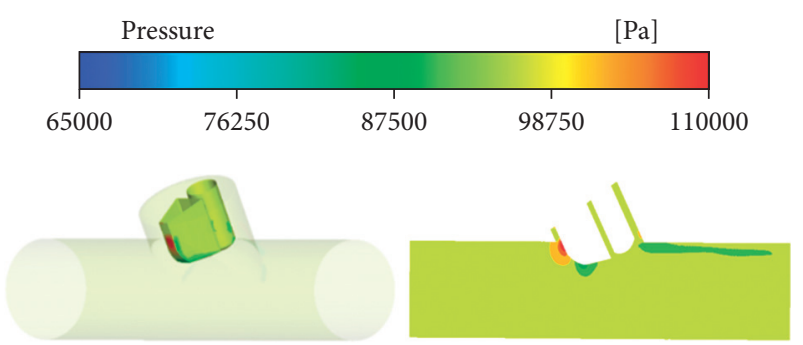

(a)
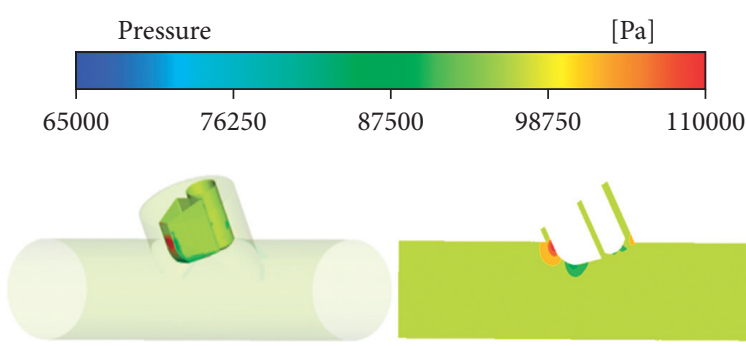

(b)

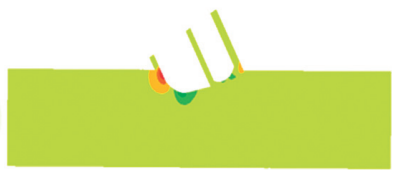

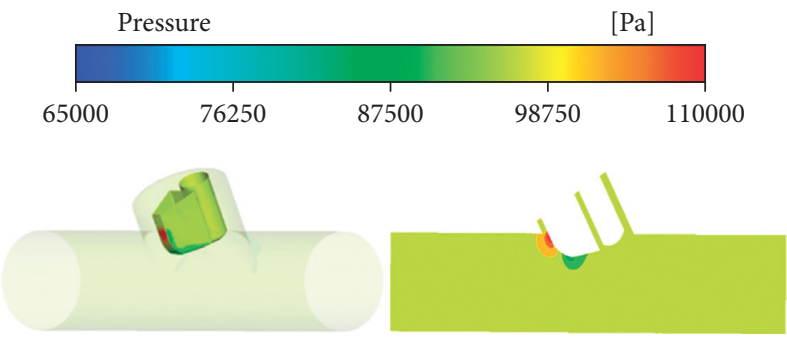

(c)

Figure 19: Pressure contours. (a) $T=7$. (b) $T=10$. (c) $T=12$.

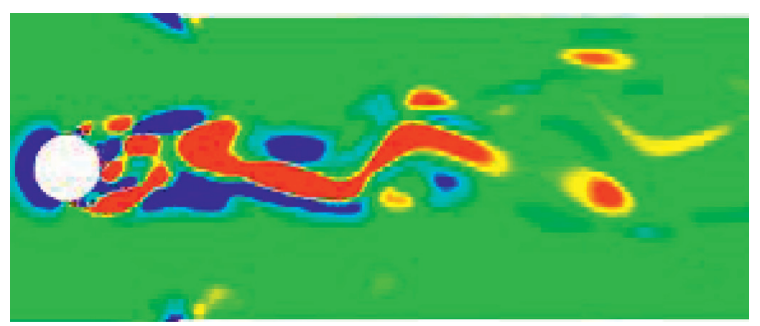

(a)

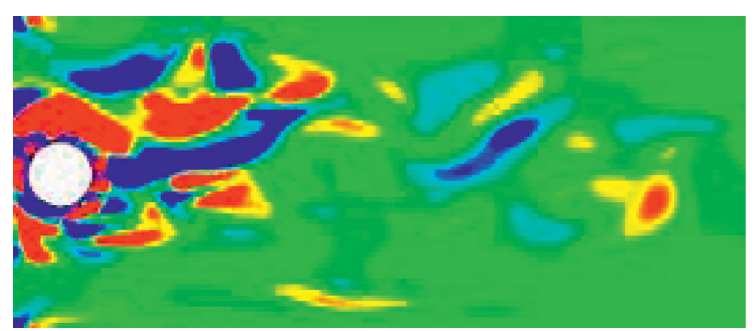

(b)

FIgURE 20: Vorticity contours. (a) Vorticity contour of single casing.

(b) Vorticity contour of thermocouple with interference device.

vortex wake. Figure 20(b) indicates that boundary layer separation also occurs on the casing surface; however, due to the interference device, the periodic vortex shedding phenomenon in the casing wake region is disrupted, the vortex shedding frequency is changed, and the vortex wake is shortened. Therefore, the existence of an interference device can avoid the resonance phenomenon of a thermowell and improve its safety.

5.3. Solid Field Analysis. By studying the effects of three different loads on the thermowell, it was found that the impact of temperature is inevitable on the stress and deformation. Therefore, considering the coeffect of the two loads on the thermowell, the effect of a certain single load on the thermowell will no longer be discussed to reduce the repetitive work while ensuring the calculation accuracy.

Under the coeffect of pressure and temperature, the deformation contour of the thermowell with the interference device is shown in Figure 21. It can be seen from the figure that the most severe deformation occurs at the bottom of the thermowell due to high gas temperature. The thermowell and the interference device undergo large bending deformations as well as expansion to varying degrees. As the

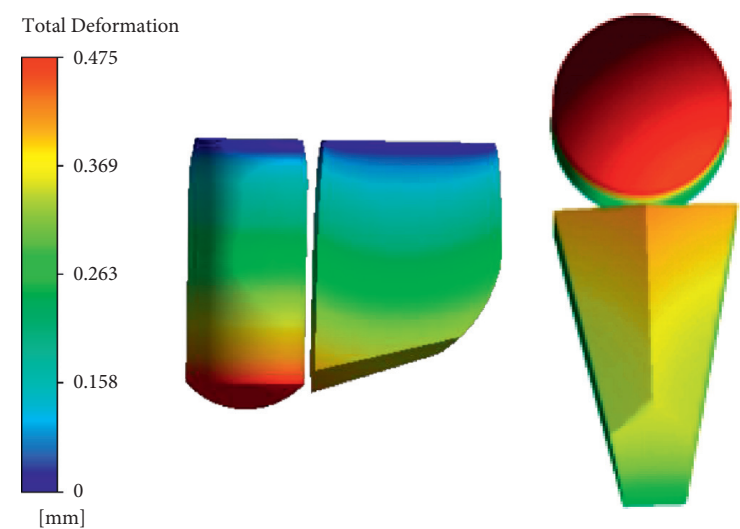

FIGURE 21: Deformation contour of thermowell and interference device.

deformation of the thermowell and the interference device causes the distance between them to be narrowed, it is necessary to fully consider the installation distance between the thermowell and the interference device to avoid squeezing damage due to deformation. The gas impact is concentrated on the bottom of the thermowell. Although the 


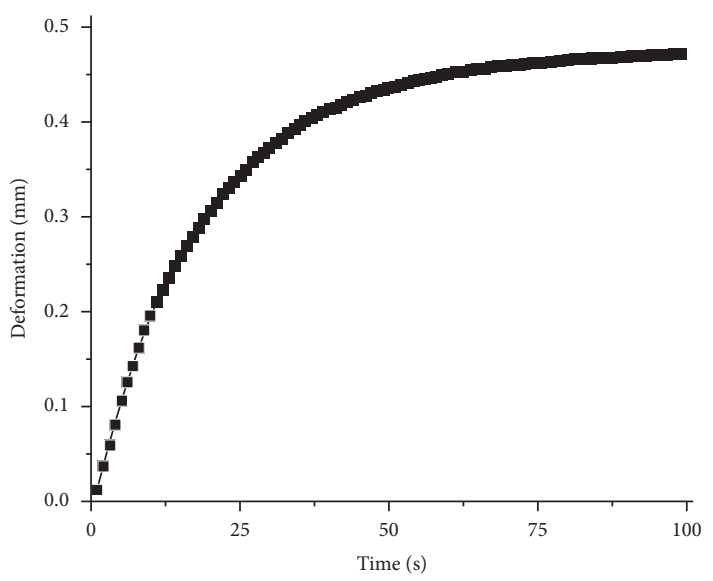

(a)

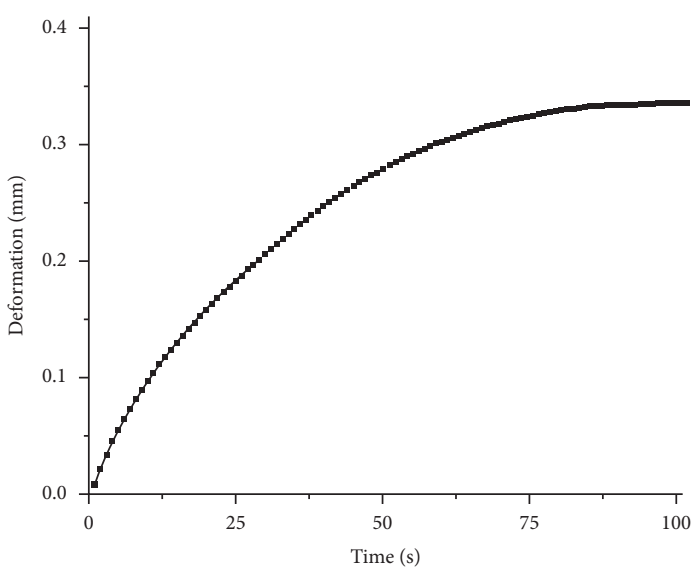

(b)

Figure 22: Variation of displacement and deformation with time. (a) The displacement deformation with time at Point 1 . (b) The displacement deformation with time at Point 2.

maximum deformation area is the same as that without the interference device, with the interference device, the maximum deformation of the thermowell is considerably decreased by $57.2 \%$ from $1.12 \mathrm{~mm}$ to $0.4786 \mathrm{~mm}$, significantly reducing the danger of the thermowell deformation.

Since the maximum deformation of the thermowell and the interference device occurs at the bottom of the structure, Point 1 and Point 2 in Figure 16 are set as the monitoring points at the bottom of the structure. The displacement deformation changing with time at monitoring Points 1 and 2 is given in Figure 22. It can be seen that the response speed of the thermowell deformation under load is faster and the deformation tends to balance at $60 \mathrm{~s}$; om the other hand, the response speed of the interference device to deformation is slower, and the interference device tends to balance at $80 \mathrm{~s}$. The deformation at both positions is in a stable equilibrium state after $80 \mathrm{~s}$.

The displacement of the thermowell and the interference device in the $X$ and $Y$ directions along the height direction are as shown in Figure 23. The monitoring line segments of the thermowell and the interference device are Line 1 and Line 2 demonstrated in Figure 16. Based on the data extracted from Line 1, the displacement of the thermowell goes mainly in the $X$-axis direction with the bottom of the thermowell deformed the most, and the displacement deformation in the height direction gradually decreases until the root constraint position drops to zero. The displacement and deformation data extracted from Line 2 indicate that the displacement is more obvious along the $Y$-axis direction and the displacement along the height direction also gradually decreases until the root constraint position is zero. There is an apparent difference between the deviation of the interference device and the thermowell, which is related to the vibration modes of different structures at a specific natural frequency.

In the equilibrium state, the equivalent stress distribution contour of the thermowell and the interference device are shown in Figure 24. The figure demonstrates that the stress peaks concentrate in the trapezoidal corners of the restraining end of the interference device, so the high-stress distribution range of the thermowell becomes smaller, and the stress concentration area disappears on the thermowell's upstream side. Figure 25 shows that the equivalent stress distribution of the thermowell and the interference device changes in the height direction. As shown in Figure 25, in the height range of $0.04 \sim 0.08 \mathrm{~m}$, the stress on one side of the thermowell almost does not change, but its value is significantly lower than before, being stable at $4 \mathrm{MPa}$; at the height above $0.08 \mathrm{~m}$ and close to the constrained position of the thermowell, the stress changes greatly along with the height and reaches the peak of $35.8 \mathrm{MPa}$ at the root. At one side of the interference device, the stress along the height direction presents approximately the same distribution law, but above $0.08 \mathrm{~m}$ the stress change tends to be more relaxed than that at the thermowell side, and the stress at the root restraint position also goes to the peak of $52 \mathrm{MPa}$. Due to the blocking effect of the interference device on the gas impact, the equivalent stress of the thermowell is reduced by $72.1 \%$ compared to that without the interference device. Hence, the interference device can effectively protect the thermowell.

Based on the two-way thermo-fluid-solid coupling analysis of the thermowell equipped with the interference device, the interference device can effectively change the flow law of the flow field. Changing the flow field cross-sectional structure can eliminate the "Carmen vortex" in the pipeline to reduce the forced vibration of the thermowell by the excitation force and avoid its resonance. The interference device can also prevent the thermowell from being exposed directly to the gas impact, ensuring that the stress amplitude at the root of the thermowell is less than the allowable shear stress of the material and thereby ensuring the structural safety of the thermowell. Due to its mass rigidity and large restricted area, the interference device can ensure the safety of its own structure.

Figure 26 is the physical map of a single thermowell, and Figure 27 is the thermowell with interference device. The research results of this paper have been recognized by the industrial partner, and the improved structural model has 


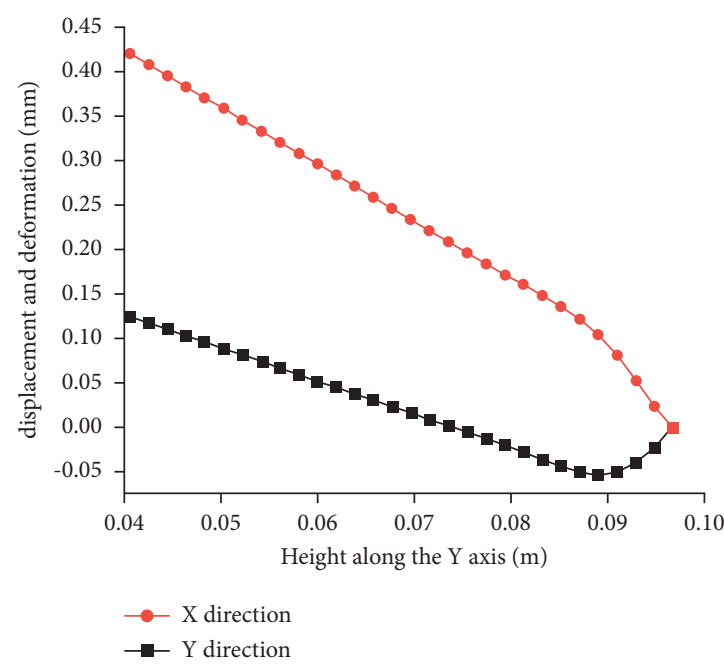

(a)

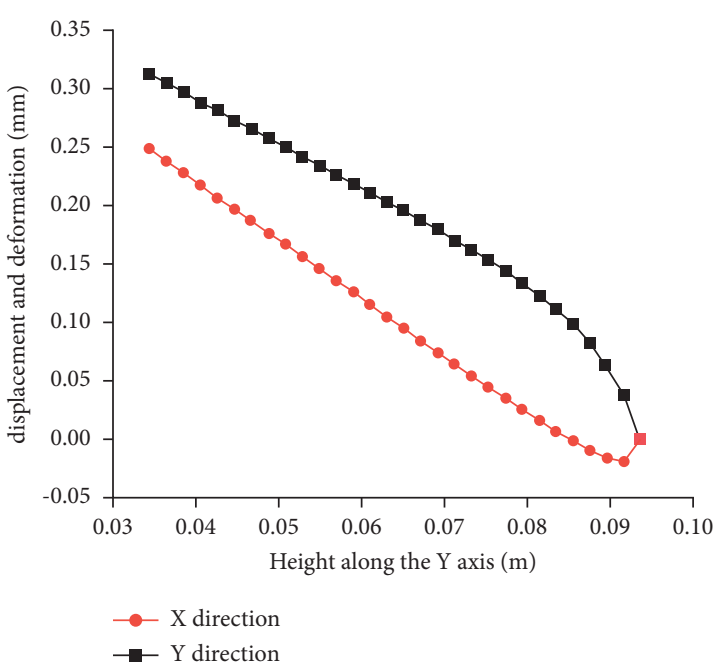

(b)

Figure 23: Variation of displacement and deformation along the height in equilibrium state. (a) Displacement and deformation along the height of Line 1. (b) Displacement and deformation along the height of Line 2.

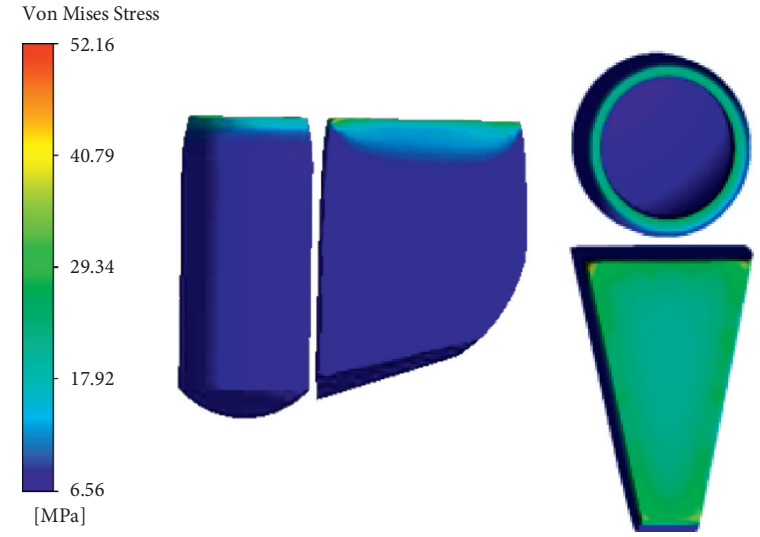

FIGURE 24: Contour of stress distribution of thermowell and interference device in equilibrium state.

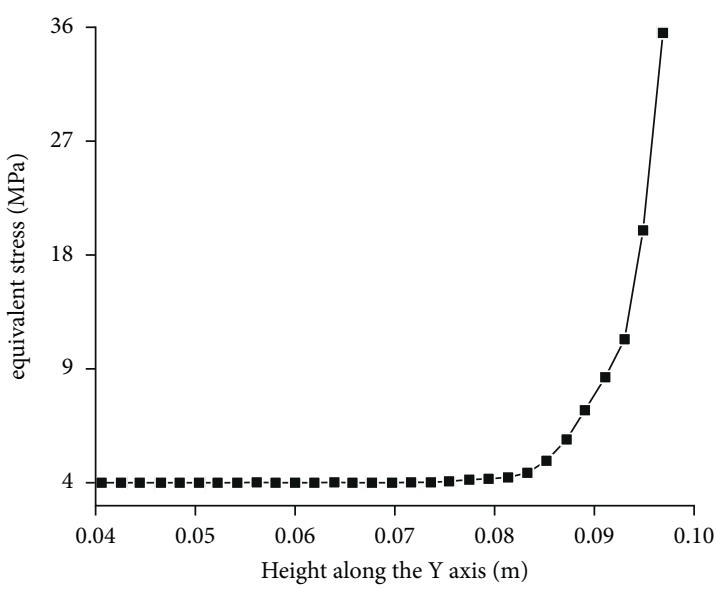

(a)

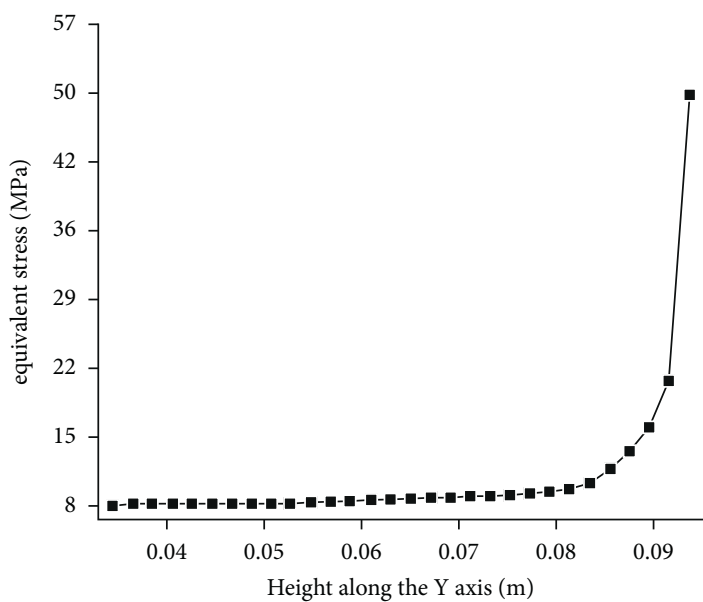

(b)

Figure 25: Distribution of equivalent stress along the height in equilibrium. (a) Distribution of equivalent stress along the height in equilibrium about Line 1. (b) Distribution of equivalent stress along the height in equilibrium about Line 2. 


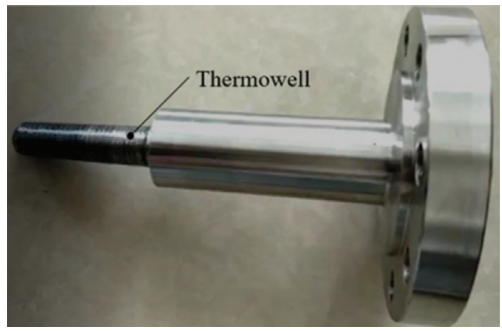

FIgURE 26: Single thermowell.

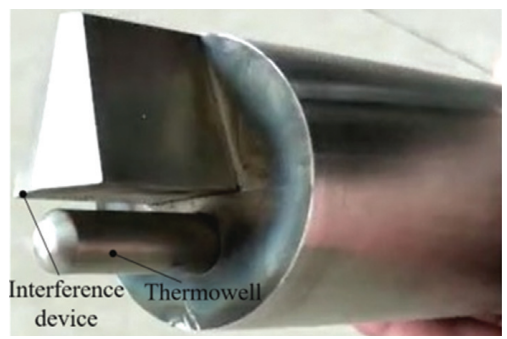

FIGURE 27: Thermowell with interference device.

been produced and applied in real practices after debugging, which also directly proves that the results of this study are accurate.

\section{Conclusions}

Aiming at the fracture damage of thermowell in the application of petroleum cracked gas pipelines, a bidirectional thermo-fluid-solid coupling model for the thermocouple thermowell was established, and the analysis of thermowell dynamic characteristics based on bidirectional fluid-solid couplings was conducted. The interference device installation and the installation angle optimization were introduced to improve the safety of the thermowell structure and applied to the petroleum cracking gas pipeline of an enterprise. The specific conclusions are as follows:

(1) The influence of gas compressibility cannot be ignored; the vortex shedding in the wake of the thermowell, the thermal stress due to high temperature, and the pressure generated by the gas are the direct causes of damage to the thermowell.

(2) After reducing the installation angle of the thermowell, the vortex shedding in the wake area becomes nonperiodic, and the Strouhal number decreases, changing the vortex shedding frequency; meanwhile, the area of the high-voltage zone of the sleeve gradually increases, which has a stronger impact on the casing.

(3) With the interference device, the vortex shedding in the wake area of the thermowell is suppressed, avoiding the occurrence of resonance. The interference device causes low pressure being formed in front of the thermowell, which reduces the pressure difference resistance. The interference device can also prevent the thermowell from being directly exposed to the gas impact and ensure that the stress amplitude at the root of the thermowell is less than the allowable shear stress of the material, thereby ensuring the thermowell structural safety.

(4) After installing the interference device, the displacement deformation of the thermowell is reduced by $57.2 \%$, and the equivalent stress is reduced by $72.1 \%$.

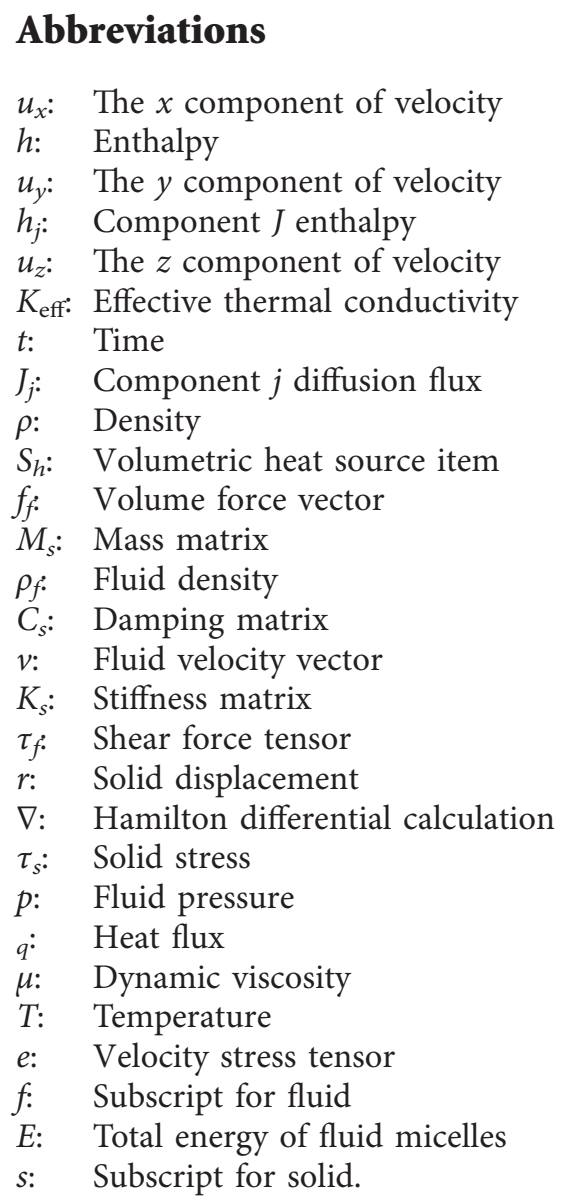

\section{Data Availability}

The data used to support the findings of this study are available from the corresponding authors.

\section{Conflicts of Interest}

The authors declare that there are no conflicts of interest regarding the publication of this paper.

\section{Acknowledgments}

This study was funded by Provincial Natural Science Foundation Project (Grant no. ZR2018MEE036).

\section{References}

[1] Q. Chen and X. Jia, "Numerical analysis on fluid excitation of thermowell," Vibration and impact, vol. 32, no. 5, pp. 119-121+143, 2013. 
[2] R. Jiang, Study on the Vortex-Induced Vibration of a cylinder, Zhejiang University, Hangzhou, China, 2013.

[3] M. I. Hairong, Study on the Characteristic Parameters of Turbulent Flow Around a Rectangular blunt Body, Harbin Engineering University, Harbin, China, 2012.

[4] E. k. Yousefabad, S. Asadi, and P. Savadkouhi, "The effect of non-uniform combustion temperature profile on thermal fatigue cracking of an air-cooled gas turbine vane," Engineering Failure Analysis, vol. 105, pp. 766-780, 2019.

[5] D. Abid and D. Mellouli, "Failure analysis of shot-sleeves used in brass high pressure die-casting process," Engineering Failure Analysis, vol. 104, pp. 177-188, 2019.

[6] Y. Liu, Y. Shan, X. Liu et al., "Effect of high temperature on thermal fatigue crack initiation life of automotive g cast iron brake disc," Journal of Mechanical Engineering, vol. 55, no. 8, pp. 97-105, 2019.

[7] I. M. Mudhaffar, A. Tounsi, and A. A. A. A. Chikh, "Hygrothermo-mechanical bending behavior of advanced functionally graded ceramic metal plate resting on a viscoelastic foundation," Structure, vol. 33, pp. 2177-2189, 2021.

[8] B. Merazka, A. Bouhadra, A. Menasria et al., "Hygro-thermomechanical bending response of FG plates resting on elastic foundations," Steel and Composite Structures, vol. 39, no. 5, pp. 631-643, 2021.

[9] C. Lu, C. Fei, Y. Feng, and Y. Zhao, "Probabilistic analyses of structural dynamic response with modified Kriging-based moving extremum framework," Engineering Failure Analysis, vol. 125, no. 1-3, Article ID 105398, 2021.

[10] B. Keshtegar, M. Bagheri, C. W. Fei, C. Lu, T. Osman, and D. K. Thai, "Multi-extremum-modified response basis model for nonlinear response prediction of dynamic turbine blisk," Engineering with Computers, no. 6, 2021.

[11] G. Zhou, S. Zeng, and Z. Li, "Two-way heat-fluid-solid coupling enhanced heat transfer mechanism of pulsating flow-induced vibration," Journal of Nanchang University, vol. 40, no. 2, pp. 103-110, 2018.

[12] L. I. Gengwang, Q. Zhang, S. Chen et al., “Thermal-fluid-solid coupling fatigue analysis of turbulent penetration of T-shaped tube," Journal of Beijing University of Chemical Technology (Natural Science Edition), vol. 47, no. 4, pp. 81-88, 2020.

[13] L. Ding, H. He, Z. Yang et al., "Thermal-fluid-solid coupling characteristics of a two-degree-of-freedom flow-induced vibration constant-temperature circular tube," Nuclear Power Engineering, vol. 67, no. S1, pp. 217-223, 2016.

[14] B. Li, G. U. O. Jiang, W. Zhao et al., "Transient dynamics analysis of thermocouple sleeve based on fluid-solid coupling," Journal of Wuhan university (engineering edition), vol. 51, no. 10, pp. 929-835, 2018.

[15] H. Miu, Y. Chen, L. Lv et al., "Fluid-induced vibration analysis of heat exchange tubes based on bidirectional fluid-solid coupling," Nuclear Technology, vol. 41, no. 5, pp. 80-86, 2018.

[16] M. Lv, Z. Ning, and K. Yan, "Thermal stability of supercavitation jets in compressible rotating gases," Journal of mechanics, vol. 50, no. 3, pp. 561-569, 2018.

[17] C. Huang, K. Luo, J. Bai et al., "Effect of liquid compressibility on supercavitation flow," Journal of Shanghai Jiao Tong University, vol. 50, no. 8, pp. 1241-1245, 2016.

[18] K. Khalil, V. Kambiz, and G. Mohamad, "Fluid-structure interaction analysis of flow and heat transfer characteristics around a flexible microcantil-ever in a fluidic cell," International Communications in Heat and Mass Transfer, vol. 75, pp. 315-322, 2016.

[19] D. G. Kang, M. J. Jhung, and S. H. Chang, "Fluid-structure interaction analysis for pressurizer surge line subjected to thermal stratification," Nuclear Engineering and Design, vol. 241, no. 1, pp. 257-269, 2011.

[20] M. Hartig, T. Schulenberg, and A. Batta, "Numerical study of fluid-structure interaction with heat transfer at supercritical pressure in a fuel rod assembly," Journal of Nuclear Engineering and Radiation Science, vol. 2, no. 1, 2016.

[21] L. Pang, S. Yi, L. Duan, W. Li, and Y. Yang, "Thermal stress and cyclic stress analysis of a vertical water-cooled wall at a utility boiler under flexible operation," Energies, vol. 12, no. 6, pp. 1170-1188, 2019.

[22] L. Xu, C. Qian, J. Liu et al., "Analysis of thermal stress of tube and plate of floating head heat exchanger," The pressure vessel, vol. 32, no. 6, pp. 55-60, 2015.

[23] T. Rui and L. Sun, "Mechanism of drag reduction around a cylinder with V-groove structure in different depths," Ship Engineering, vol. 43, no. 4, pp. 128-135, 2021.

[24] Q. Zhao, G. Jiang, and J. Hu, "Flow around a cylinder with attached prisms for drag reduction under low Reynolds number[J]," Science Technology and Engineering, vol. 21, no. 9, pp. 3468-3474, 2021.

[25] S. U. Islam, R. Manzoor, Z. C. Ying, M. M. Rashdi, and A. Khan, "Numerical investigation of fluid flow past a square cylinder using upstream, downstream and dual splitter plates," Journal of Mechanical Science and Technology, vol. 31, no. 2, pp. 669-687, 2017.

[26] M. Grioni, S. A. Elaskar, and A. E. Mirasso, "A numerical study of the flow interference between two circular cylinders in tandem by scale-adaptive simulation model," Journal of Applied Fluid Mechanics, vol. 13, no. 1, pp. 169-183, 2020.

[27] W. O. Belhocine, "Computational fluid dynamics (CFD) analysis and numerical aerodynamic investigations of automotive disc brake rotor," Australian Journal of Mechanical Engineering, vol. 16, no. 3, pp. 188-205, 2018.

[28] B. Ali and I. A. Oday, "Numerical simulation of thermally developing turbulent flow through a cylindrical tube," International Journal of Advanced Manufacturing Technology, vol. 102, no. 5-8, pp. 2001-2012, 2019. 